\title{
Influência da Variedade da Copa na Incidência da Gomose-de- Phytophthora em Porta-Enxerto de Limoeiro 'Cravo' no Estado do Piauí
}

\author{
Francisco M. P. Viana ${ }^{1}$, Francisco C. O. Freire ${ }^{1}$, José R. G. Araújo ${ }^{2}$ \& Maria N. G. Pessoa ${ }^{3}$ \\ ${ }^{1}$ Centro Nacional de Pesquisa de Agroindústria Tropical, Cx. Postal 3761, CEP 60511-110, Fortaleza, CE, fax: (085)299-1833, \\ e-mail: fmpviana@cnpat.embrapa.br; ${ }^{2}$ Universidade Estadual do Maranhão, Cx. Postal 09, CEP 65055-098, São Luís, MA, \\ fax (098) 244-0915, e-mail: gusmao@elo.com.br; ${ }^{3}$ Centro de Ciências Agrárias-UFC, Cx. Postal 12168, CEP 60356-001, \\ Fortaleza, CE, fax (085) 288-9419, e-mail: nenmaura@ufc.br
}

(Aceito para publicação em 25/10/2003)

Autor para correspondência: Francisco M. P. Viana

\begin{abstract}
Influence of scion variety on the incidence of Phytophthora gummosis in Rangpur lime rootstock in the State of Piauí, Brazil The sensitivity of the 'Brazilian Rangpur' lime (Citrus limonia) rootstock combined with three scions was evaluated for the incidence of gummosis caused by Phytophthora parasitica. The 'Pêra' sweet

orange (Citrus sinensis) scion induced the highest tolerance to rootstock resulting in a survival rate of $89 \%$ of plants up to five years after transplanting. In comparison, survival rates for the same time period were only $84.7 \%$ and $58.7 \%$, respectively, for the 'Galego' sweet lime (Citrus aurantifolia) and 'Thaiti' lime (Citrus latifolia) scions.
\end{abstract}

O Brasil ocupa posição de destaque na citricultura mundial, como principal produtor e maior exportador, respondendo por cerca de $80 \%$ do comércio mundial de suco de laranja (Citrus spp.) (Estanislau et. al., Inf. Agropec., 22:820,2001). Contudo, diversas doenças são responsáveis por perdas em viveiros e pomares, causando grandes prejuízos à citricultura nacional, desestimulando novos empreendimentos nesse agronegócio. Gomose-de-phytophthora é uma dessas doenças, que podendo se expressar de diversas formas pode causar graves perdas aos pomares cítricos (Feichtenberger, Simpósio de Citricult., p.117-136. 1988). Apesar de várias espécies do gênero Phytophthora afetarem os citros (Citrus spp.), a mais encontrada causando gomose em plantas cítricas no Brasil é a Phytophthora parasitica Dastur (=Phytophthora nicotianae B. de Haan var. parasitica [Dast.] Waterh.). A importância dessa doença aumentou após a substituição do porta-enxerto de laranjeira 'Azeda' (Citrus aurantium L.) pelo limão 'Cravo' (Citrus limonia Osbeck), espécie mais utilizada como porta-enxerto de citros no Brasil, objetivando o controle da Tristeza dos citros (Santos Filho \& Oliveira, Inf. Agropec. 22:78. 2001). Nos últimos dez anos, a pesquisa tem recomendado novas espécies e variedades de porta-enxertos como alternativos ao limoeiro 'Cravo', devido à doenças como a gomose, o declíniodos-citros e a morte-súbita. Estudos de resistência de portaenxertos à Phytophthora spp., considerando a influência da variedade copa, são poucos (Salazar, Rev. de Fruticult. 5:274. 1990; Ippolito et al., Fitopatol. Mediterr. 36:81. 1997; Feichtemberger et al., Proc. Int. Soc. Citricult. 2:854. 2002).

Objetivando a avaliação de variedades de copa de citros foi implantado um pomar em solo da classe Neosolo Quartzarênico, em região de Tabuleiros, em Parnaíba, PI, em março de 1988. A temperatura média anual do local situa-se em torno de $27,9^{\circ} \mathrm{C}$ e a umidade relativa do ar em $74,9 \%$ (Bastos et al., Embrapa, Documentos, 46, 2000). Os tratamentos foram constituídos de três variedades de copa enxertadas em cavalo de limoeiro 'Cravo': as limas ácidas 'Tahiti' (Citrus latifolia Tanaka)e 'Galego' ( Citrus aurantifolia Swingle); e a laranja 'Pêra' (Citrus sinensis Osbeck). $\mathrm{O}$ delineamento foi blocos ao acaso com parcelas constituídas de 28 plantas de cada variedade, dispostas no espaçamento $5 \mathrm{~m}$ $\mathrm{x} 7 \mathrm{~m}$. As parcelas foram irrigadas por microaspersão, com base na evaporação de um tanque classe "A". A infecção das plantas ocorreu de forma natural, tendo os primeiros sintomas surgidos dois anos após o transplantio. Foram realizadas três avaliações para gomose, em 1990, 1992 e 1994, consideraram-se dois critérios: plantas sadias e plantas vivas com lesão típica ou plantas mortas. A combinação com a copa de 'Pêra' obteve o melhor índice de sobrevivência, 89,0\%, seguida da copa de 'Galego', da qual sobreviveram $84,7 \%$ das plantas. Apesar dos bons resultados agronômicos obtidos por Figueiredo et al., Revista Brasileira de Frutic. 18:345. 1996) com a combinação Thaiti/Cravo, observou-se que tal combinação tornou o portaenxerto mais susceptível à doença, $41,2 \%$ das plantas morreram ao longo de cinco anos, enquanto na combinação mais tolerante perdeu-se apenas 11,0\%. Em estadio mais avançado da doença, observou-se lesões na copa de limão 'Tahiti'. A análise das médias pelo teste de Tukey (5\%) permitiu identificar uma tendência de maior tolerância da copa de 'Pêra', embora esta não tenha diferido estatisticamente da copa de 'Galego'. Existe relato da ausência de sintomas de gomose quando foram testados 11 clones de laranja 'Pêra' enxertados em limão 'Cravo' (Teófilo Sobrinho et al., Congr. Bras. de Frutic., Anais, 86, 1989). Verificou-se neste trabalho que a mediana susceptibilidade do limão “Cravo' a $P$. parasitica pode ser aumentada, dependendo da variedade da copa empregada". 